\title{
Double Inferior Vena Cava Associated with Double Suprarenal and Testicular Venous Anomalies: A Rare Case Report
}

\author{
Kimaporn Khamanarong ${ }^{1}$ Jarupon Mahiphot ${ }^{1}$ Sitthichai lamsaard ${ }^{1,2}$ \\ ${ }^{1}$ Department of Anatomy, Faculty of Medicine of Khon Kaen \\ University, Khon Kaen, Thailand \\ ${ }^{2}$ Center for Research and Development of Herbal Health Products, \\ Faculty of Pharmaceutical Sciences of Khon Kaen University, Khon \\ Address for correspondence Sitthichai lamsaard, PhD, Department \\ of Anatomy, Faculty of Medicine of Khon Kaen University, Khon Kaen, \\ Thailand, 40002 (e-mail: sittia@kku.ac.th).
} Kaen, Thailand

J Morphol Sci 2018;35:221-224.

\begin{abstract}
Introduction The variant courses of blood vessels are very important in considerations for retroperitoneal surgeries or interventional radiology. The present study attempted to describe a very rare case of double inferior vena cava (IVC) associated with double left suprarenal veins (LSRVs) and double right testicular veins (RTVs) in a Thai male embalmed cadaver.

Material and Methods A 70-year-old Thai male cadaver was systemically dissected and observed for the vascular distributions during gross anatomy teaching for medical students at the anatomy department of the faculty of medicine of the Khon Kaen University.

\section{Keywords}

- double inferior vena cava

- double suprarenal veins

- double right testicular veins

- anomalies

Results We found that the double IVCs were connected with the transverse interiliac vein. While the upper LSRV is a tributary of the IVC, the lower LSRV is a tributary of the left renal vein. The RTV bifurcates at about the height of the iliac cristae to form the medial and lateral RTVs, which drain into the right IVC at different heights.

Conclusion All these duplications and associated anomalies are assumed to occur during the embryological development. These anomalies are rare, but the knowledge about the possibilities of these anomalies is of great importance during retroperitoneal surgeries, and during interventional radiology.
\end{abstract}

\section{Introduction}

Double superior or inferior vena cava (IVC) are congenital variations caused by an unusual embryological development of the inferior vena cava, estimated to occur in between 0.2 and $3 \%$ of the population. ${ }^{1-3}$ Most of the cases of double IVC are incidentally found during diagnostic interventions with computed tomography (CT) or magnetic resonance imaging (MRI). ${ }^{3,4}$ Since the renal segment of the IVC has the same origin as the gonadal veins in embryogenesis, ${ }^{5}$ variations of the IVC are often accompanied by anomalies of the gonadal vein. Double IVC has significant clinical implications, especially during retroperitoneal surgeries or in the treatment of thrombotic diseases. ${ }^{6}$ Also, understanding of the variation of the left suprarenal veins (LSRVs) is clinically important for renal transplantation, laparoscopic adrenalectomy, and adrenal venous sampling. Laparoscopic adrenalectomy has become the technique of choice in adrenal surgery, and its main complication is intraoperative hemorrhage. ${ }^{7,8}$ Adrenal venous sampling has been used as the golden standard test to differentiate between unilateral adrenal adenoma and bilateral adrenal cortical hyperplasia, both of which are the most received

May 5, 2017

accepted

September 6, 2018

published online

November 8, 2018
DOI https://doi.org/

10.1055/s-0038-1675761. ISSN 2177-0298.
Copyright $\odot 2018$ by Thieme Revinter

Publicações Ltda, Rio de Janeiro, Brazil
License terms

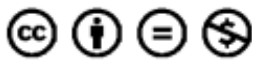


common causes of primary hyperaldosteronism. ${ }^{9}$ Likewise, prediction of the presence of duplicate testicular veins is important to avoid diagnostic and therapeutic errors during radiological and surgical procedures, especially during the ligation of varicocele, because, if unnoticed, it may cause recurrence of varicocele. ${ }^{10}$ Double IVC with coexistent double right testicular veins (RTVs) and double LSRVs are extremely rare, and awareness of these venous variations is necessary to reduce severe hemorrhage in retroperitoneal surgeries, and in interventional radiology. ${ }^{11}$ The objective of the present study was to present a case of a double IVC accompanied by double LSRVs and double RTVs.

\section{Case Report}

During a routine cadaver dissection of the abdominal region, the retroperitoneal visceral organs were exposed after removal of the anterior abdominal organs. The kidneys and the adrenal glands were dissected according to the standard technique. Double IVC was found in a 70-year-old male Thai cadaver associated with double LSRVs and double RTVs. While the upper LSRV was a tributary of the IVC, the lower LSRV was a tributary of the left renal vein (-Fig. 1).

In this case, the IVC presented normally on the right side of the abdominal aorta, but another similar vein, also identified as a left IVC on the left side of the aorta, was parallel to the normal IVC. The left renal vein joined the left IVC, which then passed to the right and joined the right IVC. Then, the common IVC traversed the normal retrohepatic route before passing through the diaphragm into the right atrium in the normal anatomical position. The right renal vein drained into the right IVC. The interiliac vein was situated ventral to the body of the $5^{\text {th }}$ lumbar vertebra. The RTV was bifurcated at the height of the iliac crest, and the medial branch drained to the right IVC below the height of the right kidney, and its lateral branch also drained to the right IVC, but just below the point of drainage of the right renal vein (-Fig. 1). The renal vessels followed the normal pattern. Both ureters lied laterally to each IVC in their course to the pelvis, with no apparent abnormalities.

\section{Discussion}

The retroperitoneal venous system develops from three paired fetal venous systems, the posterior cardinal, the subcardinal, and the supracardinal systems. ${ }^{12}$ The normal IVC is converted to a unilateral, right-sided system, consisting of four components: (1) the infrarenal segment from the right supracardinal vein, (2) the renal segment from the right supracardinal anastomosis, (3) the suprarenal segment from the right subcardinal vein, and (4) the hepatic segment from the right hepatic vein. Double IVC is considered to occur due to the persistence of both supracardinal veins. ${ }^{13,14}$ Chen et al (2011) ${ }^{11}$ reviewed 109 cases of IVC anomalies and found that 87 of them had intrailiac anastomosis. According to their classification of IVC anomalies, the case reported here is compatible with their type $2 \mathrm{~d}$, double IVC connected by transversely running interiliac vein, which is assumed to be the left common iliac vein in normal development. Double IVC is a rare and usually clinically silent venous anomaly. Discovery of
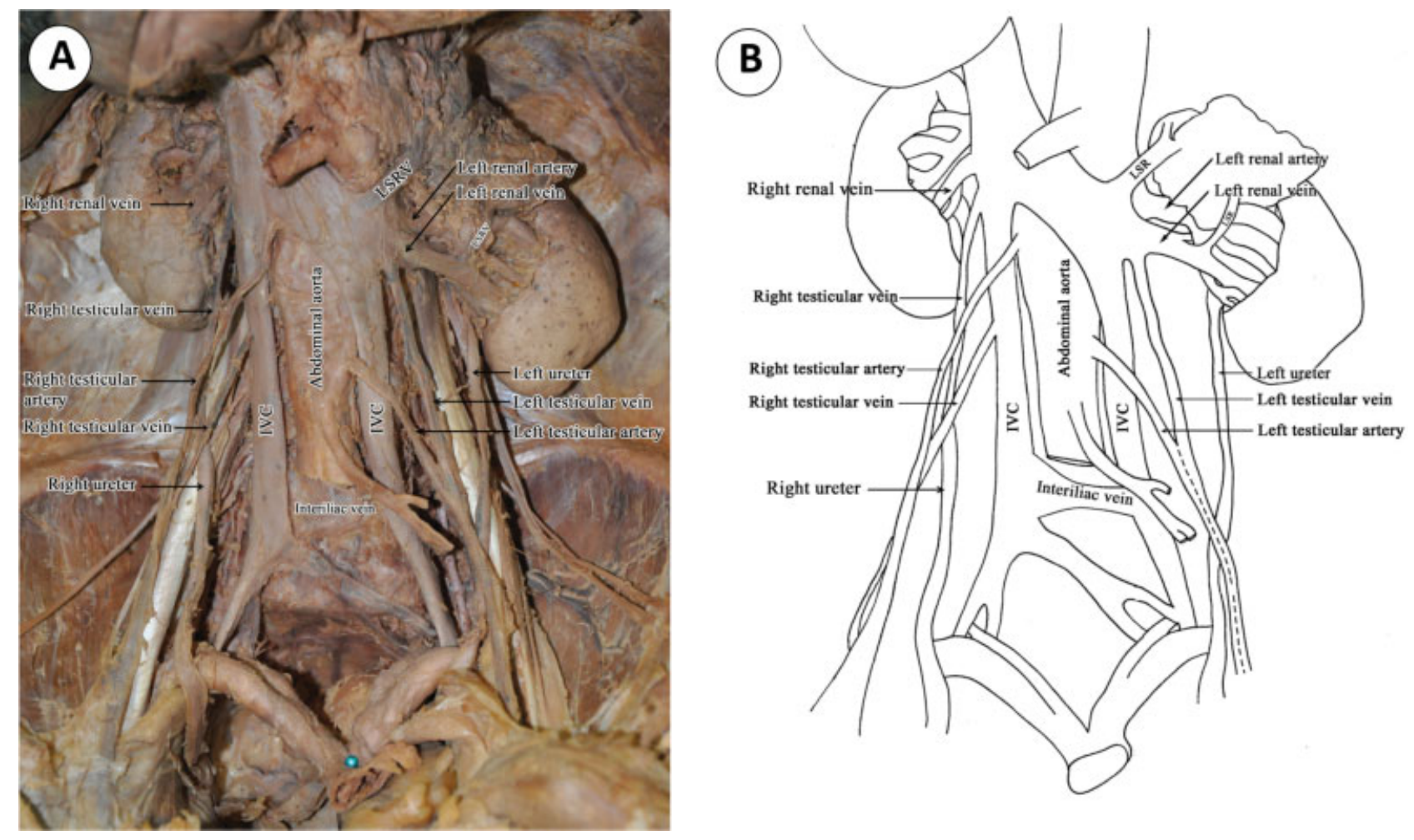

Fig. 1 (A) Photograph and (B) schematic drawing demonstrating the double inferior vena cava (IVC) interconnecting with an interiliac vein, associated with right and left suprarenal (LSR) and testicular venous anomalies. 
double IVC in the operating room would lead to unexpectedly serious technical difficulties in certain patients subjected to laparoscopic nephrectomy. ${ }^{15}$ There are several case reports of thromboembolic events occurring in patients with double IVC. ${ }^{16}$ In radiology, the presence of double IVC can be mistaken as lymphadenopathy, ${ }^{17}$ or left pyeloureteral dilatation. ${ }^{18}$ The interiliac vein might cause some problems due to unexpected hemorrhage during abdominopelvic surgeries including misdiagnosis among clinicians. ${ }^{19}$ The interiliac vein is a decisive factor in determining the strategy for venous interventional radiology, such as in IVC filter placement, because of a possible risk factor of deep venous thrombosis. ${ }^{20}$

The LSRV normally receives blood from the left suprarenal gland and drains into the left renal vein. Sebe et al examined 88 venograms and found anatomical variations in $5 \%$ of the right and in $6 \%$ of the left suprarenal veins (SRVs). ${ }^{21}$ In the adrenal venous sampling procedure, it is important to review the anatomy of the SRVs from thin slices of CT scan prior to the intervention. Catheter selection is determined according to the anatomy of the SRVs. The approach to the left SRV should be made under a different position, according to the position of the venous anatomy. Detailed knowledge of the variation of the LSRV, including double LSRVs, is critically important for the effective procedural planning and sampling interpretation. ${ }^{22}$ Also, in the laparoscopic adrenalectomy procedure, it is important to know the anatomical variation to avoid the risk of massive intraoperative hemorrhage. Excessive traction of an adrenal gland without control of the principal adrenal vein on the left may injure the renal vein or the IVC. ${ }^{21}$ The gonadal veins may be misinterpreted as a double IVC because they run close to the ipsilateral IVC, particularly the left gonadal vein that drains into the left renal vein. ${ }^{11}$

Embryologically, the SRVs are formed by the stem of the subcardinal veins. ${ }^{23}$ In the present case, double left SRVs were identified, the upper left SRV as a tributary of the IVC, and the lower SRV as a tributary of the left renal vein. Malposition of the left suprarenal gland during the embryonic development might cause a small distance of transposition of an intra-abdominal organ from their usual anatomic locations, which in turn alters its vascular variation. ${ }^{24}$ Recently, we have found a case of double LSRVs in a 62year-old-male cadaver. In this case, other vascular anomalies were not found and both left SRVs drained into the left renal vein. ${ }^{25}$ About the anomalies of testicular veins, bifurcation of the RTVs is very rare. The right testicular vein develops from the lower part of the right subcardinal vein. The terminal bifurcation of the RTV might be due to the bifurcation of the right subcardinal vein during its development. ${ }^{26}$

\section{Conclusion}

To our best knowledge, this is the first record of the coexistence of double IVC, double LSRVs, and double RTVs. Those anomalies have particular importance for the various interventions that take place during retroperitoneal surgeries, and are essential for venous interventional radiologists, as well as for orthopedists, to reduce the risk of serious hemorrhage during surgical treatment and to avoid operative complications.

\section{Acknowledgments}

We gratefully acknowledge those who donated their body to the Department of Anatomy of the Faculty of Medicine of the Khon Kaen University, as well as their families for granting permission for the dissection of the cadavers. We would also like to thank Professor Yukifumi Nawa for the critical reading of this manuscript. The present study was approved by the Research and Ethics Committee of the Faculty of Medicine of the Khon Kaen University with the approval number HE591077.

\section{References}

1 Iamsaard S, Kanla P, Arunyanart C. Double superior vena cava: two cases in Thai cadavers. Acta Medica Academica, 2014, vol. 43, n.2, p.170-171. http://dx. doi: . Doi: 10.5644/ama2006-124.117

$2 \mathrm{Ng}$ WT, Ng SS. Double inferior vena cava: a case report of three cases. Singapore Med J 2009;50(06):211-213http://smj.sma.org. sg/5006/5006cr5.pdf

3 Saad KR, Saad PF, Amorim CA, et al. Duplication of the inferior vena cava: case report and a literature review of anatomical variation. Journal of Morphological Sciences 2012;29(01):60-64http://jms.org.br/PDF/v29n1a14.pdf

4 Kapetanakis S, Papadopoulos C, Galani P, Dimitrakopoulou G, Fiska A. Anomalies of the inferior vena cava: a report of two cases and a short review of the literature. Folia Morphol (Warsz) 2010;69(03):123-127

5 Itoh M, Moriyama H, Tokunaga Y, et al. Embryological consideration of drainage of the left testicular vein into the ipsilateral renal vein: analysis of cases of a double inferior vena cava. Int J Androl 2001;24(03):142-152 Doi: 10.1046/j.1365-2605.2001.00286.x

6 Radermecker MA, Van Damme H, Kerzmann A, Creemers E, Limet R. Association of abdominal aortic aneurysm, horseshoe kidneys, and left-sided inferior vena cava: report of two cases. J Vasc Surg 2008;47(03):645-648 Doi: 10.1016/j.jvs.2007.08.053

7 Bonjer HJ, Sorm V, Berends FJ, et al. Endoscopic retroperitoneal adrenalectomy: lessons learned from 111 consecutive cases. Ann Surg 2000;232(06):796-803

8 Suzuki K, Ushiyama T, Ihara H, Kageyama S, Mugiya S, Fujita K. Complications of laparoscopic adrenalectomy in 75 patients treated by the same surgeon. Eur Urol 1999;36(01):40-47

9 Stack SP, Rösch J, Cook DM, Sheppard BC, Keller FS. Anomalous left adrenal venous drainage directly into the inferior vena cava.J Vasc Interv Radiol 2001;12(03):385-387 Doi: 10.1016/S1051-0443 (07)61922-8

10 Tubbs RS, Salter EG, Oakes WJ. Unusual drainage of the testicular veins. Clin Anat 2005;18(07):536-539 Doi: 10.1002/ca.20135

11 Chen H, Emura S, Nagasaki S, Kubo KY. Double inferior vena cava with interiliac vein: a case report and literature review. Okajimas Folia Anat Jpn 2012;88(04):147-151 https://www.jstage.jst.go.jp/ article/ofaj/88/4/88_147/_pdf

12 Mayo J, Gray R, St Louis E, Grosman H, McLoughlin M, Wise D. Anomalies of the inferior vena cava. AJR Am J Roentgenol 1983; 140(02):339-345 Doi: 10.2214/ajr.140.2.339

13 Bass JE, Redwine MD, Kramer LA, Huynh PT, Harris JH Jr. Spectrum of congenital anomalies of the inferior vena cava: cross-sectional imaging findings. Radiographics 2000;20(03):639-652 Doi: 10.1148/radiographics.20.3.g00ma09639

14 Mathews R, Smith PA, Fishman EK, Marshall FF. Anomalies of the inferior vena cava and renal veins: embryologic and surgical considerations. Urology 1999;53(05):873-880

15 Kennealey PT, Saidi RF, Markmann JF, Ko DSC, Kawai T, Yeh H. Duplicated inferior vena cava - something to consider in the evaluation of a living donor renal transplant. Dial Transplant 2009;38(10):420-422 Doi: 10.1002/dat.20363 
16 Kouroukis C, Leclerc JR. Pulmonary embolism with duplicated inferior vena cava. Chest 1996;109(04):1111-1113 Doi: 10.1378/ chest.109.4.1111

17 Klimberg I, Wajsman Z. Duplicated inferior vena cava simulating retroperitoneal lymphadenopathy in a patient with embryonal cell carcinoma of the testicle. J Urol 1986;136(03): 678-679

18 Gay SB, Armistead JP, Weber ME, Williamson BR. Left infrarenal region: anatomic variants, pathologic conditions, and diagnostic pitfalls. Radiographics 1991;11(04):549-570 Doi: 10.1148/ radiographics.11.4.1887111

19 Inamasu J, Guiot BH. Laparoscopic anterior lumbar interbody fusion: a review of outcome studies. Minim Invasive Neurosurg 2005;48(06):340-347 Doi: 10.1055/s-2005-915634

20 Anne N, Pallapothu R, Holmes R, Johnson MD. Inferior vena cava duplication and deep venous thrombosis: case report and review of literature. Ann Vasc Surg 2005;19(05):740-743 Doi: 10.1007/ s10016-005-5674-6

21 Sèbe P, Peyromaure M, Raynaud A, Delmas V. Anatomical variations in the drainage of the principal adrenal veins: the results of
88 venograms. Surg Radiol Anat 2002;24(3-4):222-225 Doi: 10.1007/s00276-002-0021-X

22 Daunt N. Adrenal vein sampling: how to make it quick, easy, and successful. Radiographics 2005; 25(1, Suppl 1)S143-S158 Doi: 10.1148/rg.25si055514

23 Moore KL, Persaud TVN, Torchia MG. The Developing human clinically oriented embryology. 9th ed. Elsevier Saunders2013, p. $292,514$.

24 Oztürk NC, Uzmansel D, Kara A, Oztürk H. Variation in the position, relation and vasculature of left suprarenal gland: a case report. Surg Radiol Anat 2010;32(10):985-988 Doi: 10.1007/s00276-0100636-2

25 Khamanarong K, Sawatpanich T, Chaichum A. Double left suprarenal vein and its clinical implication. Srinagarind Medical Journal2015;30(7):http://thailand.digitaljournals.org/index.php/ SMJ/article/download/28336/27550

26 Nayak BS, Rao KM, Shetty SD, Sirasanagandla SR, Kumar N, Guru A. Terminal bifurcation of the right testicular vein and left testicular arterio-venous anastomosis. Kathmandu Univ Med J (KUMJ) 2013;11(42):168-170 